\title{
PENANAMAN TOGA SEBAGAI WUJUD CINTA LINGKUNGAN
}

\author{
Ririn Hamidah ${ }^{1}$, Dina Mayan Sari ${ }^{2}$, Dwi Mayasari ${ }^{3}$, Novendra Halim ${ }^{4}$ \\ Fakultas Ekonomi Universitas PGRI Adi Buana Surabaya \\ Email :hamidahririn@yahoo.com ${ }^{1}$
}

\begin{abstract}
Kegiatan pengabdian pada masyarakat (PPM) yang berbentuk pelatihan ini diperuntukan bagi ibu-ibu PKK di Desa Lundo Kecamatan Benjeng Kabupaten Gresik. Tujuan PPM ini adalah meningkatkan pengetahuan dan ketrampilan menanam TOGA. Meningkatkan pengetahuan dan ketrampilan menanam TOGA pada para ibu-ibu PKK desa Lundo, serta menyebarluaskan informasi dalam bentuk media tertulis tentang cara menanam TOGA dengan memanfaatkan barang bekas lebih tepatnya yaitu botol air minum bekas. Metode yang digunakan yaitu active learning dan parcipatory learning, yang meliputi ceramah, praktek penanaman TOGA dan dilanjutkan dengan diskusi hasil pelatihan ini. Hasil pelatihan ini menunjukkan pengetahuan dan ketrampilan budidaya TOGA ibu-ibu "PKK" meningkat dari 56\% menjadi 70,9\%; pengetahuan dan ketrampilan pengolahan TOGA meningkat dari $61 \%$. Informasi tentang TOGA telah diterima $99 \%$ peserta pelatihan.
\end{abstract}

Kata Kunci : lundo, penanaman toga, botol bekas

\section{PENDAHULUAN}

Desa Lundo merupakan salah satu desa yang terletak di Kecamatan Benjeng Kabupaten Gresik. Desa Lundo terdiri dari 6 dusun yaitu Dusun Lundo, Dusun Ngegot, Dusun Patuk, Dusun Telbek, Dusun Jemek, dan Dusun Gempal. Penduduk Dusun Lundo mayoritas bermata pencarian sebagai petani, hampir $75 \%$ masyarakatnya bermata pencaharian sebagai petani. Sebagian ibu di Desa Lundo sudah menanam tanaman obat keluarga (TOGA), karena sudah mengetahui khasiatnya dan secara teknis mampu mengolahnya namun belum memahami secara ilmiah, sehingga perlu dilakukan pelatihan dan pengadaan bahan tertulis tentang khasiat tumbuhan obat keluarga secara ilmiah tetapi masih banyak warga Lundo yang belum sadar akan pentingnya penanaman obat keluarga ini di lingkungan mereka. Selain itu penanaman TOGA juga dilakukan sesuai kemampuan mereka dan hanya sangat terbatas jumlahnya, padahal lahan pekarangan masih luas.

Para ibu di Desa Lundo aktif mengikuti kegiatan PKK yang dibina oleh desa dan rutin dilaksanakan tiap bulan. Pada kegiatan PKK sering kali mendapatkan tambahan materi penyuluhan oleh berbagai pihak. Dari hasil survey dan wawancara, pada kegiatan PKK belum pernah mendapatkan penyuluhan dan pelatihan tentang penanaman TOGA. Untuk membantu pemerintah dalam menggalakkan TOGA sekaligus menambah pengetahuan dan ketrampilan bagi ibu-ibu PKK di Desa Lundo dalam hal penanaman TOGA perlu dilakukan penyuluhan dan pelatihan. Berdasarkan kenyataan yang ada di Desa Lundo bahwa banyak keluarga yang menanam TOGA yang diolah sebagai obat untuk pertolongan pertama bagi keluarga, dan didukung oleh kenyataan bahwa di dusun Kasuran masih banyak lahan terbuka, maka kondisi tersebut berpotensi untuk kegiatan pemanfaatan lahan untuk memelihara tanaman penghasil bahan obat tradisional. Tanaman tersebut antara lain belimbing wuluh, jambu biji, temu ireng, temu lawak, ingu, bengle, jahe, markisah, kembang telang, kenanga, pepaya, mindi, jarak, kumis kucing, apokat, melati, nangka, jambe, dan tanaman bahan makanan atau minuman lainnya. Di desa Lundo lebih tepatnya pada dusun Lundo dan dusun Ngegot sebesar $20 \%$ dan $15 \%$ masyarakatnya membuat serta menjual jamu.

Upaya penanaman dan pemanfaatan TOGA sebagai pengobatan tradisional dan mengetahui karakteristik pengobatannya sangat diperlukan. Karena tidak banyak warga yang mengetahui akan pentingnya penanaman obat 
keluarga disekitar pekarangan rumahnya. Selain itu, diperlukan juga pengetahuan tentang bagaimana cara menanam toga agar tidak mudah busuk atau mati dikarenakan di Desa Lundo sering banjir maka cara yang bisa dilakukan adalah menanam toga dengan cara digantung menggunakan media botol bekas atau barang bekas.

Oleh karena itu, disini divisi tanaman TOGA KKN-PPM UNIPA Surabaya memberikan kontribusi berupa teknik penanaman yang baik bagaimana karena seperti yang kita ketahui di benjeng sering terjadi banjir, jadi bagaiaman agar penanaman tumbuhan itu terhindar dari banjir, disini kami memberikan saran teknik tanaman gantung yang lebih efisien.

\section{METODE PELAKSANAAN}

Metode yang digunakan dalam divisi penanaman Toga adalah dengan melakukan pendekatan kepada staff desa dengan tujuan untuk memperoleh gambaran secara garis besar keadaan masyarakat Desa Lundo.

Dalam melaksanakan kegiatan tersebut maka yang harus kita lakukan antara lain seperti yang terstruktur yakni:

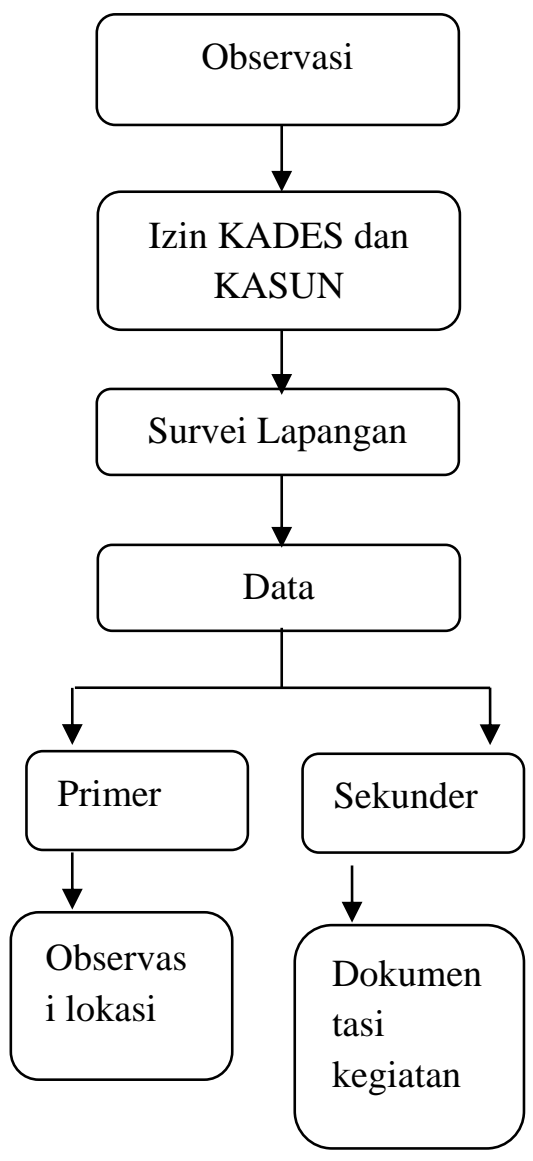

Target sasaran kegiatan adalah para ibu PKK karena memiliki kedudukan fungsional dan strategis sebagai media komunikasi dan interaksi berbagai pendapat dan sekaligus pelaksananya. Kegiatan dimulai dari kegiatan rutin pertemuan ibu-ibu PKK tingkat dusun pada setiap bulannya. Target sasaran minimal 25 orang.

\section{Metode Kegiatan PPM}

a. Active and participatory learning:

- Ceramah dan Diskusi

- Praktek penanaman TOGA

$b$. Membuat Media Informasi TOGA berdasarkan ketersediaan jenis tumbuhan di sekitar lingkungan.

\section{IHASIL DAN PEMBAHASAN}

Berdasarkan kegiatan penanaman dan pemanfaatan Toga yang telah kami lakukan di lingkungan Desa Lundo hasil yang kami peroleh dalam program kegiatan ini berjalan dengan baik. Identifikasi masalah didapatkan dan dirumuskan berdasarkan hasil observasi dimana lingkungan di daerah ini memiliki curah hujan yang tinggi yang menyebabkan mudah banjir. Untuk Menjadikan tumbuhan didaerah ini mudah untuk hidup, diperlukan perawatan yang sangat baik untuk menjaga tumbuhan supaya tumbuh dengan baik. agar mendapatkan hasil yang maksimal maka diperlukan perawatan yang baik dan benar.

Kemudian dalam kegiatan penanaman dan pemanfaatan Toga yang telah kami lakukan di lingkungan Desa Lundo hasil yang kami peroleh dalam program kegiatan ini berjalan dengan baik. Warga sangat antusias dalam melaksanakan kegiatan penanaman dan pemanfaatan Toga bagi kesehatan di lingkungan desa. Walaupun sebagian masyarakat minat akan tanaman toga ini agag sedikit kurang, mungkin mereka sudah sedikit banyak tahu manfaat akan tanaman toga yang di berikan oleh teman-teman. tanaman yang di promosikan oleh divisi kami yaitu antara lain sebagai berikut:

1. Kunyit

berikut ini enam manfaat kunyit bagi kesehatan: 

a. Meredekan nyeri lambung dan magh
b. Bisa mencegah serangan jantung
c. Menghambat diabetes
d. Mencegah kanker
e. Melindungi otak
f. Mencegah nyeri sendi

2. Temu Lawak (Curcuma xanthorhiza roxb) Manfaat temulawak untuk mengobati sakit kuning, diare, maag, perut kembung dan pegalpegal. Terakhir juga bisa dimanfaatkan untuk menurunkan lemak darah, mencegah penggumpalan darah sebagai antioksidan dan memelihara kesehatan dengan meningkatkan daya kekebalan tubuh.

3. Jahe

Mengandung senyawa oleoresin yang lebih dikenal sebagai gingerol yang bersifat sebagai antioksidan, sebagai komponen bioaktif antipenuaan. Bermanfaat melindungi lemak/membran dari oksidasi, menghambat oksidasi kolesterol, dan meningkatkan kekebalan tubuh, masuk angin, sakit kepala, sakit kepala sebelah, mabuk kendaraan dan param untuk anggota badan yang terkilir.

4. Kencur

Bermanfaat mengobati Influenza pada Bayi, Menghilangkan lelah, minuman kesegaran, radang lambung, batuk dan melancarkan haid.

5. Daun Dewa

Manfaat Efek farmakologis daun dewa adalah antikoagulan (koagulan=zat yang mempermudah dan mempercepat pembekuan darah), mencairkan bekuan darah, stimulasi sirkulasi, menghentikan perdarahan, menghilangkan panas, dan membersihkan racun. Mengatasi kejang pada anak dan beberapa jenis pendarahan. Untuk mengatasi luka terpukul, tak datang haid, pendarahan pada wanita, pembengkakan payudara, batuk, dan muntah darah, tumor, kutil dan kanker.

6. Daun kemangi

Konsumsi lalap kemangi secara rutin dapat mencegah bau mulut, dayn kemangi atau sari daun kemangi dapat menyembuhkan penyakit diare, gangguan pada vagina, nyeri payudara, hingga mengatasi batu ginjal dan albuminaria. Daun kemangi terbukti berkhasiat ampuh mengatasi keluhan flu, diare, sakit kepala, cacingan, sembelit. Selain itu, penelitian tersebut juga membuktikan manfaat daun kemangi untuk mengobati perut kembung, maag, badan lesu, masuk angin, hingga mengatasi kejang. Aroma dari daun kemangi juga dapat digunakan sebagai obat nyamuk.

7. Tempuyung (sonchus arvensis 1)

Di dalam daun tersebut terkandung kalium berkadar cukup tinggi. Membuat batu ginjal berupa kalsium karbonat tercerai berai, karena kalium akan menyingkirkan kalsium untuk bergabung dengan senyawa karbonat, oksalat, atau urat yang merupakan pembentuk batu ginjal. Endapan batu ginjal itu akhirnya larut dan hanyut keluar bersama urine.

\section{Sambiloto}

Bermanfaat melindungi hati, sambiloto juga dapat menekan pertumbuhan sel kanker. Hal ini disebabkan karena senyawa aktifnya, yakni Andrographolide, menurunkan ekspresi enzim CDK4 (cyclin dependent kinase 4). Andrographolide yang terkandung memiliki sifat melindungi hati (hepatoprotektif), dan terbukti mampu melindungi hati dari efek negatif galaktosamin dan parasetamol.

\section{Beluntas}

Secara tradisional daun beluntas digunakan sebagai obat untuk menghilangkan bau badan, obat turun panas, obat batuk, dan obat diare. Daun beluntas yang telah direbus sangat baik untuk mengobati sakit kulit. Disamping itu daun beluntas juga sering dikonsumsi oleh masyarakat sebagai lalapan.

10. Jambu biji

Penyakit Yang Dapat Diobati : Diabetes melitus, Maag, Diare (sakit perut), Masuk angin, Beser; Prolapsisani, Sariawan, Sakit Kulit, Luka baru dan jus jambu biji bisa untuk menyembuhkan penyakit demam berdarah

\section{Keji beling}

Keji beling atau orang jawa menyebutnya dengan nama "sambang geteh." Tumbuhan ini memiliki banyak mineral seperti kalium, kalsium, dan natrium serta unsure mineral lainnya. Disamping itu juga terdapat asam silikat, tannin, dan glikosida. Kegunaannya sebagai obat disentri, diare (mencret) dan obat batu ginjal serta dapat juga sebagai penurun 
kolesterol. Daun tanaman ini selain direbus untuk diminum airnya, juga dapat dimakan sebagai lalapan setiap hari dan dilakukan secara teratur. Daun keji beling juga kerap digunakan untuk mengatasi tubuh yang gatal kena ulat atau semut hitam, caranya dengan cara mengoleskan langsung daun keji beling pada bagian yang gatal tersebut. Demikian pula untuk mengobati penyakit lever (sakit kuning), ambien (wasir) dan maag.

\section{Langkah-langkah pelaksanaan divisi TOGA}

kegiatan

Ibu-ibu PKK diundang untuk berkumpul di salah satu rumah warga di masing-masing dusun di Desa Lundo untuk diberi penyuluhan dan pelatihan. Sebelum demontrasi dan praktek para peserta pelatihan diberi ceramah tentang cara penanaman TOGA dengan media barang bekas seperti botol minum bekas dan lain-lain.

Perlengkapan dan bahan yang perlu disiapkan untuk menanam tanaman toga dengan media botol bekas :

a. Siapkan botol bekas yang sudah tidak terpakai ukuran 1,5 L jenis botol plastik

b. Pisau, gunting, tali atau kawat

c. Batu kerikil

d. Tanah

e. Pupuk

f. Jenis tanaman toga

g. Air secukupnya

\section{Cara pembuatan :}

- Berikan lubang pada bagian bawah botol bekas sebagai tempat keluarnya air ketika saat menyiram tanaman

- Potong dan bentuk lubang besar pada bagian kiri dan kanan atas botol agar tanaman tersebut dapat merambat kebagian sisi kanan dan kiri botol

- Berikan lubang pada tutup botol sebagai pengait tali atau kawat agar tanaman toga dapat digantung didepan rumah anda

- Lapisan paling bawah adalah kerikil agar air siraman tanaman toga dapat diserap dengan baik dan tidak terbuang sia-sia

- Selanjutnya masukkan tanah yang sudah tercampur dengan pupuk diatas kerikil tersebut

- Tanam tanaman toga jenis apapun yang anda inginkan
- Siram secara teratur tanaman toga anda dan gantung didepan rumah untuk memeprcantik hiasan rumah anda

Selain botol bekas minuman, anda bisa juga menggunakan pipa paralon. Namun, untuk pipa paralon membutuhkan berbagai peralatan yang lebih dan tentu saja teknik yang menanam yang lebih tinggi. Untuk itu, bagi para pemula disarankan saja untuk menggunakan botol bekas minuman sebagai media untuk membuat tanaman hidroponik.

\section{Prosedur Kegiatan Penanaman TOGA}

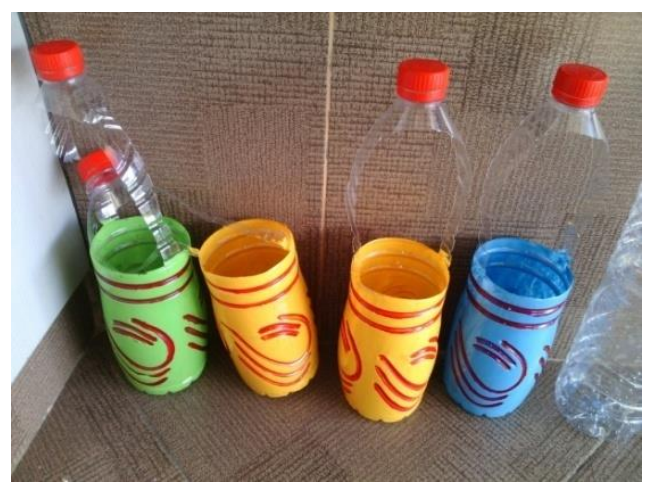

Gambar 1. Botol bekas yang sudah di cat oleh bank sampah

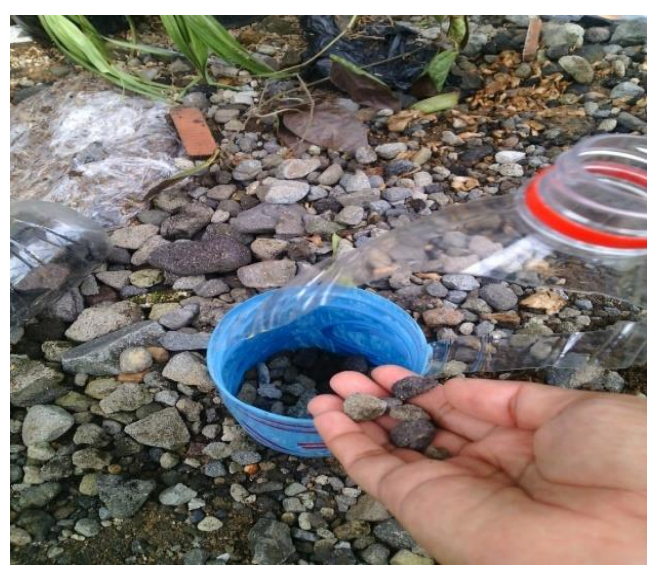

Gambar 2. Masukkan kerikil ke dalam botol 


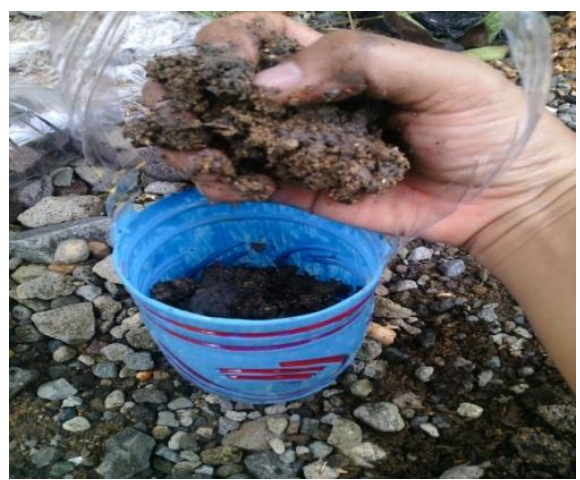

Gambar 3. Masukkan tanah yang dicampur pupuk ke dalam botol

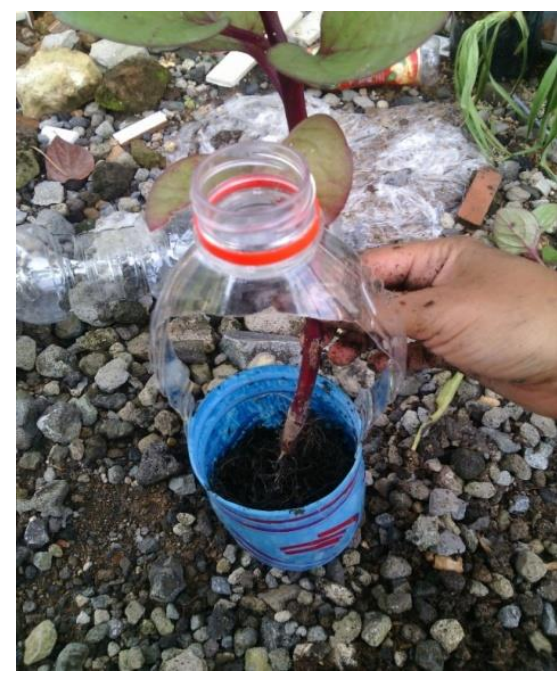

Gambar 4. Kemudian tanam tumbuhan kedalam botol

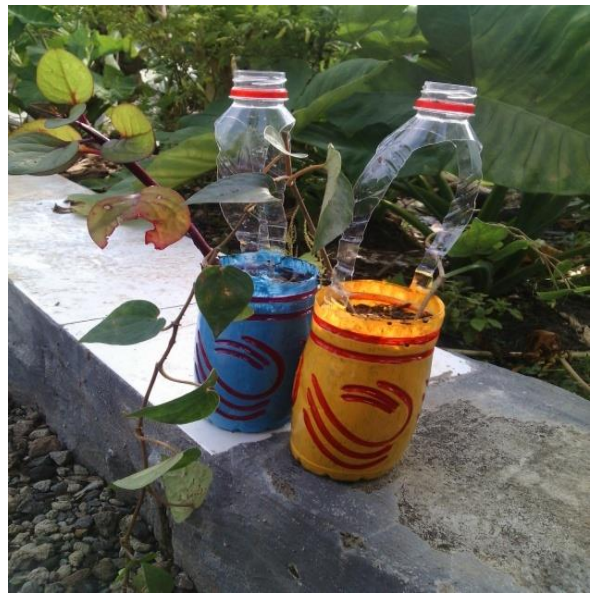

Gambar 5. Hasil media tanam TOGA dari botol air mineral bekas

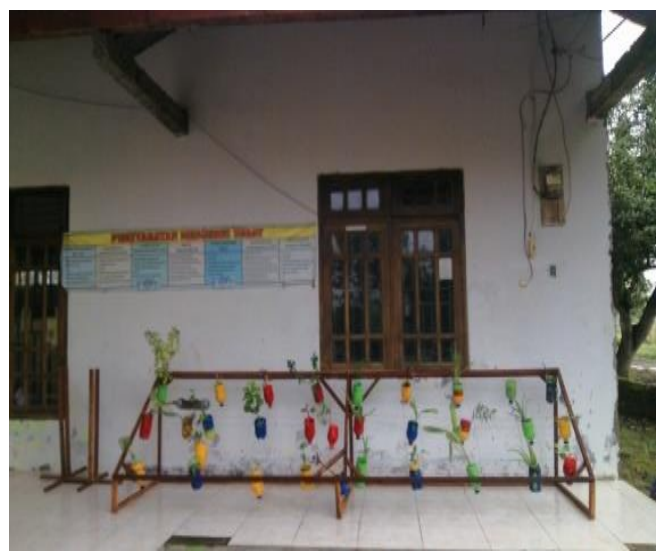

Gambar 6. tanaman TOGA di Balai Desa Lundo

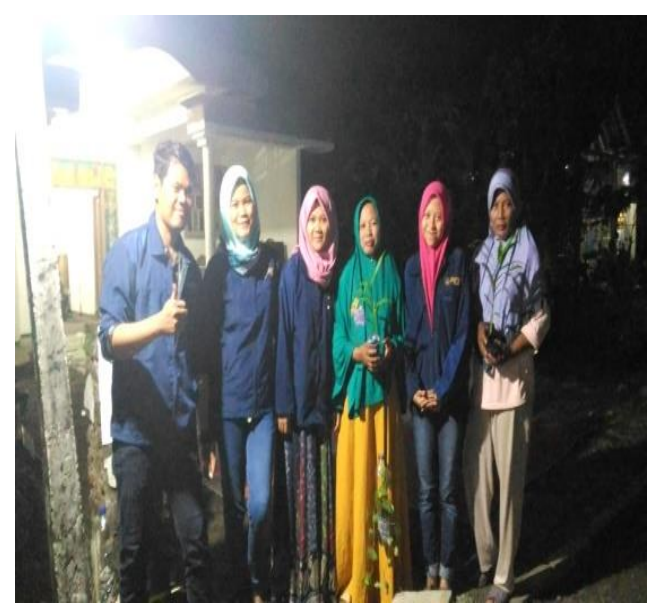

Gambar 7. kegiatan di Dusun Lundo

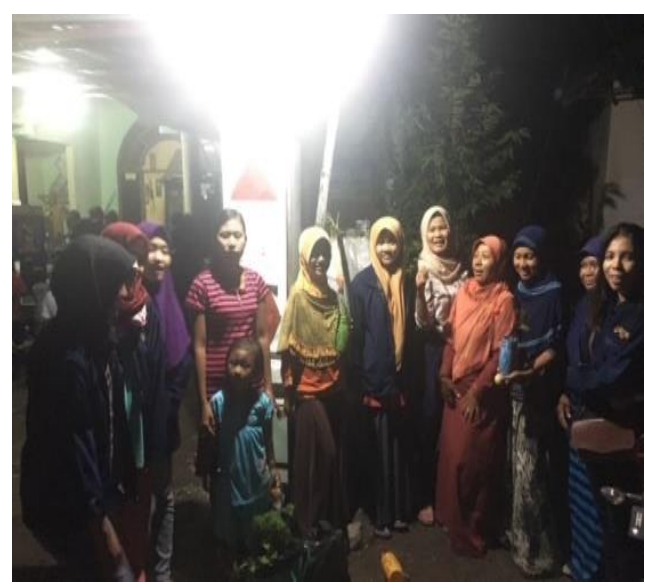

Gambar 8. Kegiatan di Dusun Ngegot 


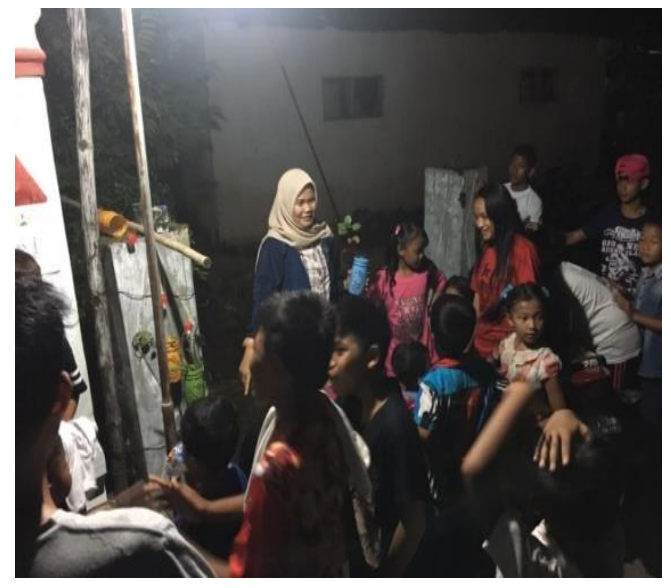

Gambar 9. Kegiatan di dusun patuk

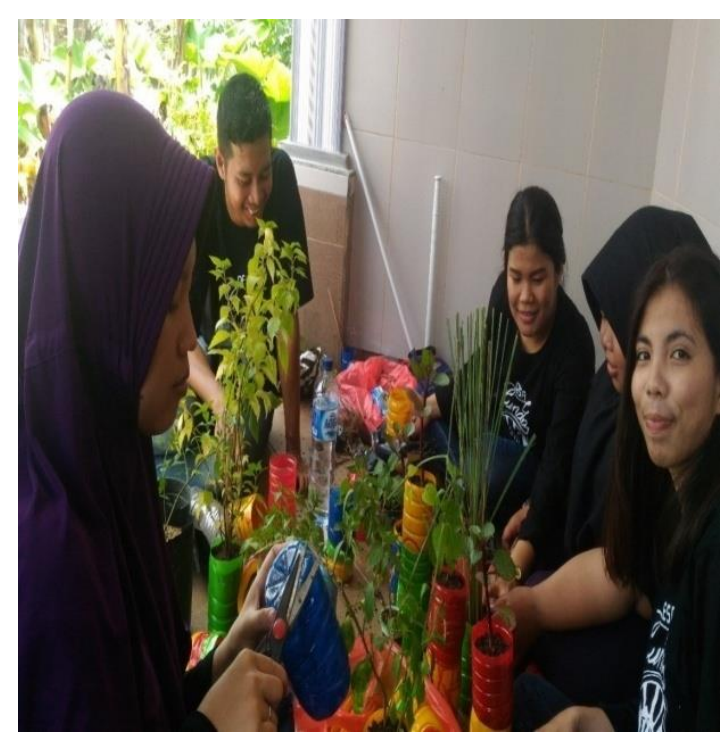

Gambar 10. Proses menanam Tanaman TOGA

\section{SIMPULAN DAN SARAN}

Kesimpulan yang dapat kami ambil dari kegiatan kami selama di desa dalam program matakuliah KKN-PPM di divisi penanaman TOGA ini adalah, warga desa memerlukan sebuah teknik penanaman secara praktis yang jauh dari kebanjiran karena seperti yang kita ketahui daerah benjeng terkenal daerah yang rawan banjir, jadi tugas kita sebagai divisi penanaman TOGA bagaimana cara kita agar tanaman tersebut tetap hidup walaupun saat kebanjiran. Jadi kesadaran warga desa khususnya Desa Lundo untuk berperan aktif agar menjaga tanaman yang ada disekitar rumah khususnya tanaman obat keluarga di halaman atau lingkungan sekitar rumah, karena sangat bermanfaat bagi keluarga.
Saran kami sebagai mahasiswa KKN dalam divisi penanaman TOGA adalah teknik yang sudah ada perlu untuk di praktekkan dan dikembangkan lebih baik lagi, agar mendapatkan hasil yang maksimal. Dan mendapatkan manfaat akan tanaman itu sendiri.

\section{UCAPAN TERIMA KASIH}

Dengan berakhirnya kegiatan KKN kami selama di desa Lundo, banyak hal yang tentunya tidak dapat kami laksanakan secaraindividu. Ucapan terimakasih kami berikan kepada seluruh anggota divisi kami, Divisi Penanaman TOGA. Kami bekerja keras untuk dapat menyelesaikan tugas kami. Berkat kekompakan kami dan semangat kami, 90\% target yang kami rancang telah tercapai.

Yang kedua ucapan terimakasih kami berikan kepada ketua-ketua perangkat dusun yang terbagi menjadi 6 Dusun. Serta ucapan terimakasih sebesar-besarnya kepada para warga yang yang ikut serta dalam kegiatan ini dan kami dokumentasikan beberapa bukti usaha dalam bentuk foto dan kuisioner.

Yang terakhir adalah ucapan terimakasih kepada rekan-rekan dari divisi lain yang turut serta membantu dalam seluruh kegiatan kami.

Serta tidak lupa ucapan sebesar-besarnya kami tujukan kepada Universitas PGRI Adi Buana Surabaya. Berkat adanya program studi KKN ini, kami dapat menjadi lebih dewasa untuk bekal kami di masa depan. Baik dalam bergaul, berbaur, berinteraksi, bersosialisasi, berdedikasi dan memberikan pelayanan kepada masyarakat.

\section{DAFTAR PUSTAKA}

Anonim. Kecamatan Benjeng Dalam Angka. 2016. www.bps.go.id diakses tanggal 17 februari 2017

Chia. 2013. Tanaman Obat Keluarga, macam dan Manfaatnya sebagai pengobatan. http://bedcoverandsprey.blogspot.com diakses tanggal 27 februari 2017

Edukasi dan Penanaman TOGA. 2017. http://kkn.undip.ac.id diakses tanggal 27 februari 2017

Este. 2012. Tanaman Obat Keluarga. http://sininjamerah.blogspot.com diakses tanggal 21 februari 2017 
Kurniasih, Lilis. 2009. Fungsi dan Manfaat Tanaman TOGA. http://liliskurniasih.wordpress.com diakses tanggal 1 maret 2017

Rini, Audia. 2015. Menanam Tanaman Obat.http://webblogkkn.unsyiah.ac.id diakses tanggal 25 februari 2017

Rizhoe. Tanaman Obat Keluarga. 2017. http://id.m.wikipedia.org diakses tanggal 25 februari 2017

Rizki. 2016. Tanaman Obat. http://tanamanhiasandaun.com diakses tanggal 20 februari 2017

Yakin, Ainul. 2016. DATA PROFIL DESA DAN KELURAHAN DESA LUNDO, 1. DATA POTENSI DESA, 2. DATA PERKEMBANGAN. Gresik.

Yanuar. 2014. Mari Belajar. http://yanuarimaesa.blogspot.com diakses tanggal 20 februari 2017

Yudhe. 2013. Tanaman Obat Keluarga dan Manfaatnya. www.yudhe.com diakses tanggal 1 maret 2017. 
ABADIMAS ADI BUANA Volume 02, Nomer 2, 01 Oktober 2017 